\title{
SILVIANO SANTIAGO, RICARDO PIGLIA E AS NARRATIVAS DO CONE SUL
}

\author{
Maria Antonieta Pereira \\ Universidade Federal de Minas Gerais
}

Tu conheces, leitor, o monstro delicado Hipócrita leitor, meu igual, meu irmão.

Charles Baudelaire

as anotações cotidianas tinham como matériaprima a "decepção do leitor", do leitor que insistia com que apenas narrasse os dias terríveis na prisão.

Silviano Santiago

Por fim, quando se diz - como Arlt - que todo crítico é um escritor fracassado, não se está confirmando de fato um mito clássico do romance policial?

Ricardo Piglia

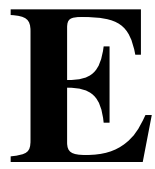

ntre as várias similitudes presentes na narrativa latinoamericana da atualidade, destaca-se a problematização, por parte de certos escritores, da categoria autor. Ao invés de permanecerem cultuando aquele que, historicamente, foi catalogado como a força originária da obra, os escritores têm desenvolvido a tarefa de dilapidar os resquícios de aura que circundam a autoria. Considerada, por Foucault, como um elemento discursivo estreitamente vinculado tanto à propriedade e à classificação de textos quanto ao esclarecimento das relações de semelhança e diferença entre eles, a função autor também se 
caracteriza por seu distanciamento em relação ao indivíduo concreto que redige um texto. Enquanto escritores-críticos profundamente inseridos nos contextos histórico-culturais do Brasil e da Argentina, Silviano Santiago e Ricardo Piglia desenvolvem uma produção textual que encena não somente a História das nações mas também a transmutação do eu-que-escreve no eu-que-narra. Ao privilegiar o percurso pelos territórios contestados da nacionalidade e da identidade, esses escritores lidam com fenômenos emergentes que, tensionando sua atividade criadora, resultam em mesclagens experimentais anunciadoras de novas formas de contar histórias. Ao narrar-se a si mesmo, o escritor também se apropria de outra função social: simula um eu-que-edita e, por essas vias, examina e discute o caráter e as atribuições do leitor, seu parceiro e rival no mercado de signos.

O que à primeira vista parece um desejo enciclopédico de exercitar todas as prerrogativas ligadas às mitologias da escrita literária, se examinado mais de perto, indica o momento crítico em que uma prática textual dedica-se a discutir seus próprios cânones através da revisão das regras elementares de seu funcionamento. Interpelada, primeiramente, pela reprodutibilidade técnica, a obra de ficção conviveu com muitos questionamentos de seu estatuto, entre os quais podemos destacar, neste final de século, a concorrência dos variados tipos de tela. Se o esgotamento de certas formas permite a restauração de gêneros e estilos, as transformações por que passa a literatura atual parecem configurar uma crise de crescimento, no sentido de que novas categorias textuais começarão a circular no mercado de signos. As mudanças que se anunciam dizem respeito não apenas aos elementos intrínsecos da narrativa, mas a todo um aparato social, econômico e mercadológico que condiciona a existência do relato. A tematização insistente de suas condições de produção mostra como a literatura revê seus paradigmas de construção textual e, num processo reflexivo jamais visto anteriormente, avalia, seleciona, descarta e recicla aquilo que lhe parece matéria do narrável. Preocupada em redimensionar os sujeitos que a realizam, a literatura transforma-se em objeto de si 
mesma, numa política de resistência ao desaparecimento de certa identidade e, ao mesmo tempo, de rendição à mutação inexorável das formas.

Nesse sentido, a relação criador-obra, muitas vezes considerada como base da invenção estética, abandona seu estatuto, forjado à imagem e semelhança da divindidade, para se constituir como palco de contendas desses dois elementos, entre os quais se imiscui a função editor como uma curiosa forma do autor recusar a paternidade do texto que escreve. Assim, arquitetada sobre a tríade autor-texto-editor, a obra parece direcionar-se para o objetivo principal de fustigar a posição do leitor, impedindo que ele permaneça na comodidade de quem apenas desfruta de uma escrita voltada para seu entretenimento. Dessa forma, a seta disparada por certos escritores latino-americanos da atualidade parece atingir em cheio uma prática de leitura em cujo imaginário persiste uma América Latina identificada com seus próprios mitos de origem tribal e nacional, que caberia ao leitor reconhecer, para com eles se identificar. As imagens exóticas do realismo fantástico, o regionalismo, os temas campestres e o narrador heróico e melancólico vão sendo deslocados para contextos altamente complexos, em que um olhar construído pela vida cosmopolita das tecnópoles latino-americanas define e redimensiona o que deve ser narrado.

Irônico e desencantado, o narrador da atualidade dessacraliza os fatos da História nacional, abordando-os a partir da perspectiva do cotidiano, das histórias pessoais e dos conflitos existentes no espaço em que se forjam as narrativas fundadoras. Ao narrar a perda de certo discurso nacional, a ficção discute também seu papel de narradora oficiosa de relatos dessa natureza. Exatamente por isso, intervém na posição confortável do leitor, transformando-o em epicentro de um debate em que seu papel é redefinido não só pelo que diz respeito a sua postura frente à obra em questão mas, especialmente, pelo que tange aos conceitos veiculados por ela e que lhe exigem uma revisão das categorias discursivas através das quais sua leitura foi construída. À medida que se perde uma certa 
estrutura narrativa, perde-se também uma determinada concepção de identidade e pátria. Se a pátria é aquilo que dizemos dela, ao narrador contemporâneo tem sido creditada a tarefa social de recontar sua trajetória, inclusive quando o escritor que o inventa trabalha com uma versão fradulenta do processo de criação. No mundo da globalização e da multiculturalidade, em que os elementos nacionais se mesclam de forma vertiginosa a elementos estrangeiros, a ficção poderia funcionar como um espaço de resistência identitária. Curiosamente, nesse momento crucial da História, o autor questiona o papel que lhe atribui sua comunidade lingüística e, na prática, redefine sua participação no cenário das narrações - escreve a História através da história, como sempre o fez, mas atribui sua escritura a uma personagem por ele próprio inventada.

$\mathrm{Na}$ América Latina, os exemplos mais interessantes de escritores que recusam sua própria função, e apresentam-se ao leitor simplesmente como editores de determinado texto, podem ser localizados no Silviano Santiago de Em liberdade e no Ricardo Piglia de Nome falso-uma bomenagem a Roberto Arlt.

\section{Três diário e um editor}

A problematização da instância autoral surpreende o leitor nas primeiras páginas de Em liberdade, quando a advertência intitulada "Nota do Editor" e assinada por Silviano Santiago traça um breve histórico da criação do romance. ${ }^{1}$ Essa narrativa da narrativa, ao informar o leitor sobre as condições de produção textual, desenvolve uma simulação de autenticidade e, nesse sentido, transforma a maneira de se classificar o texto produzido e as circunstâncias que o geraram. Disfarçado pela máscara editorial, o autor recorda o fingimento como um importante recurso de criação

${ }^{1}$ SANTIAGO, 1981. 
ficcional, presente em momentos significativos da literatura brasileira, como no arcadismo mineiro, o qual, por sua vez, é tematizado nas páginas de Em liberdade, através do poeta inconfidente Cláudio Manuel da Costa. O experimento lingüístico de Silviano Santiago aponta para o uso do pastiche também como uma espécie de convenção literária, amplamente praticada por determinada tendência da ficção contemporânea.

As marcas da função editor aparecem também na profusão de dados históricos dirigidos ao leitor com a intenção de aprisioná-lo numa formação discursiva presidida pela intensificação do efeito de real. Assim, acontecimentos relativos à prisão e à libertação de Graciliano Ramos recebem uma datação precisa e têm como suporte o depoimento de personagens da época - como Getúlio Vargas, Filinto Müller, Sobral Pinto, José Lins do Rego, Herman Lima - ou da própria filha do escritor, Clara Ramos. Contudo, a ilusão de realidade torna-se mais intensa quando o editor narra as supostas condições em que teria produzido Em liberdade. A referência ao mundo da pesquisa universitária - bolsa da CAPES, Alexandre Eulálio, INL, pai do poeta Octávio Mora, Universidade de Rutgers propicia um cenário adequado ao convencimento do leitor sobre o caráter realístico do que se narra.

Outro mascaramento da função autoral surge, no início do romance, a partir do texto "Sobre esta edição", escrito por Silviano Santiago mas assinado por um suposto O Editor. A essa nova encenação se acrescenta um post scriptum firmado apenas com a expressão O mesmo, a qual reitera o processo de composição da obra. Nesse texto, o pseudo-editor assume o papel do pesquisador acadêmico que informa o leitor sobre a situação material em que se encontravam os apontamentos de Graciliano, ora transformados em romance. É interessante observar que, para falar deles, o editor usa a expressão "os originais", fato que, agregado aos demais, reforça novamente a idéia de que Silviano Santiago seria apenas um elemento que teria mediado as relações autor-leitor. Referindo-se à biografia de Graciliano Ramos e a dados da História do Brasil, 
durante o período Vargas, o editor apresenta quatro razões que, segundo ele, "fazem-se necessárias a fim de evitar equívocos maiores".

Contudo, tais considerações servem justamente para intensificar os equívocos sobre os quais o suposto editor elabora hipóteses de investigação da obra e, em última instância, transgride a regra de composição textual relativa à originalidade e à autoria. Embora $E m$ liberdade não tivesse a pretensão de ser "uma primeira versão" de Memórias do cárcere, o diário de Graciliano constituiria o último capítulo desse romance, fato comprovado pelas declarações de Ricardo Ramos, filho do escritor. No testemunho familiar, estariam presentes os elementos que, conforme a astúcia do editor, remeteriam às "sensações de liberdade" misturadas a "uns restos de prisão" que caracterizam a escrita do diário. Citando-se a si próprio, o texto introdutório de Em liberdade anuncia que, em algum momento dessa obra, o escritor Graciliano Ramos declara que suas anotações cotidianas tencionavam trabalhar com a decepção do leitor, negando-se a oferecer-lhe o quadro sacrificial da prisão e, pelo contrário, advertindo-o sobre o papel transformador da celebração da liberdade. Evidentemente, esse era o Graciliano inventado pela ficção de Silviano Santiago: numa entrevista de 1991, ele afirma que sua intenção era apresentar ao leitor "o desejo violento de afirmar os sentimentos vitais" "2 que, a partir de terorias nietzscheanas, provocasse a rejeição de uma existência baseada em sofrimento e morte. De forma que, mais uma vez, o romance problematiza a organização de certas categorias textuais e investe na mutação do ato de ler, a partir de novas proposições escriturais. Ao final do relato, temos um autor que poderia ser identificado com o escritor Silviano Santiago, que finge ser Graciliano Ramos que, por sua vez, profetiza sua própria escritura como uma incorporação do poeta árcade Cláudio Manuel da Costa:

${ }^{2}$ SANTIAGO, 1991. 
Será meu o desejo de vida, quando a noite se abater sobre a Casa do Real Contrato das Entradas. (...) Não ponho aspas. As palavras são minhas. Incorporá-las-ei ao romance, de tal forma que são elas que escrevem; é o estilo delas que se segue, continua, até chegar a preencher as linhas de uma folha. (...) Cláudio será Graciliano. Graciliano redige, mas quem escreve é Cláudio. ${ }^{3}$

Na terceira recomendação de "O Editor", torna-se explítica a concepção de leitor que dialoga com a fatura do romance. Referindose ao "crítico faminto de contradições", o narrador estabelece uma falsa distinção entre o que seria o racionalismo planejado da ficção e a anarquia ocasional do diário, quando, de fato, ele próprio se apresenta como o responsável pela publicação de um texto que pratica a mesclagem dos gêneros e, em última análise, dos estilos individuais. De qualquer forma, Em liberdade escolhe seu leitor virtual no interior de um público restrito, habituado às investigações acadêmicas, históricas e literárias, obsedado por fragmentos, detalhes e incongruências que desafiam seu repertório analítico a se restaurar incessantemente no estabelecimento de uma verdade que, bem o sabe, é provisória e parcial. É ainda pela tematização do leitor que Silviano Santiago introduz na narrativa o exemplo clássico de Kafka e Max Brod, em que o segundo teria sido encarregado de destruir as obras do primeiro. Escolhido como depositário do desejo de morte do escritor, Brod recusou seu papel e, apostando na afirmação de "sentimentos vitais", preservou para a posteridade verdadeiras obras-primas da ficção do século XX. Não por acaso, em Nome falso- bomenagem a Roberto Arlt, Ricardo Piglia vale-se do mesmo argumento de autoridade para desenvolver o que ele próprio chama de identificação da escrita "com o crime, o logro, a falsificação, o roubo". ${ }^{4}$

${ }^{3}$ SANTIAGO, 1981, p.234.

${ }^{4}$ PIGLIA, 1988, p. 51. 


\section{Dois editores de três contos}

As relações entre Franz Kafka e Max Brod são mencionadas, na literatura de Ricardo Piglia, pelo polonês Vladimir Tardewski, personagem do romance Respiração artificial que teria se exilado na Argentina e descobrira singulares relações entre a vida e a obra do escritor judeu-polonês e o nazismo, bem como concluíra que $O$ discurso do método, de Descartes, fora o campo fecundo que teria permitido, mais tarde, a floração de Mein kampf, de Hitler. ${ }^{5}$

Contudo, em Nome falso é que se analisa de forma mais pertinaz a dupla Kafka/Brod a qual se converte em tema inspirador do relato à medida que fornece os elementos básicos de sua construção, ou seja, a tematização das prerrogativas de um leitor especializado, tal como ocorre no romance de Silviano Santiago. Em 1991, Piglia declara a respeito desse conto: "O relato está escrito com a idéia de que a crítica literária é como uma novela policial. Esta seria a idéia inicial que arma este texto. (...) Segunda questão: eu queria escrever um relato com a história de alguém que havia conhecido um escritor famoso como Arlt."

Ao escrever um conto para discutir o papel da crítica literária em relação a um escritor consagrado, Piglia também procede a uma alteração das hierarquias e prioridades comumente desenvolvidas no mundo editorial. Ao invés de o ensaio surgir a posteriori e como leitura da obra de arte, ele aparece mesclado à própria obra, como seu eixo, tema e razão de ser. Se a obra é sempre a criação original, da qual o ensaio constitui um texto segundo ou simulacro, em Nome falso dá-se a erosão desse princípio legitimador, e o estudo crítico é tratado como uma narrativa. A ressemantização textual torna-se extremamente fecunda à medida que investiga questões de grande importância para a ficção contemporânea, em sua relação com novas

5 PIGLIA, 1987.

${ }^{6}$ PIGLIA, 1991. 
linguagens mundiais - informática, robótica, genética - e com a cultura da oralidade e da imagem. Editor de um manuscrito de duvidosa autoria, Ricardo Piglia agudiza as reflexões sobre a natureza da arte de escrever, mostrando como a sobrevivência dessa prática depende de tais considerações.

Por isso, não casualmente, o escritor Ricardo Piglia transformase na personagem Ricardo Piglia - crítico literário, narrador, detetive e editor em busca de "Luba", obra inédita de Roberto Arlt. O excesso de atribuições da personagem constitui uma pista de que o texto foi escrito tendo em vista o questionamento da propriedade autoral. Tal fato é corroborado pelo desenvolvimento da trama, especialmente quando a personagem Kostia, detendo os manuscritos de "Luba", declara que, se fosse Max Brod, teria publicado O castelo em seu nome - desejo que acaba por realizar relativamente ao conto de Arlt, editando-o como se fosse seu. Em nota de pé de página, o detetive Ricardo Piglia argumenta a favor de Kostia, admitindo que a atitude mais interessante de Brod seria o roubo da autoria dos textos de Kafka:

Não teria sido mais agradável (não podemos pensar que era isso o que ele desejava?), para o gênio distante e perverso de Franz Kafka, um Max Brod que usurpa a fama do defunto e que na hora de morrer revela a alguém (a outro testamenteiro serviçal, a outro Max Brod) a secreta autoria daqueles textos? (...) (o fato de que não me tenha sido possível publicar esse texto - como era minha intenção - independentemente, precedido por um simples ensaio introdutório, demonstra - como se verá - que de alguma maneira submeti-me à mesma prova que Max Brod) ${ }^{7}$

Percebemos nessas reflexões que, a exemplo do conto "As ruínas circulares", de Jorge Luis Borges, o narrador de Nome falso imagina um labirinto formado por sujeitos e textos - Max Brod funcionando como personagem de Kafka e engendrando outro Max Brod testamenteiro - que remete à própria situação do editor do

7 PIGLIA, 1988, p. 50. 
conto de Roberto Arlt. E se, segundo Kostia, "para poder sair do labirinto, primeiro é preciso perder-se”, encontramos aí uma situação que caracteriza a fraude textual como um dispositivo capaz de engendrar diferentes enunciações. Nesse caso, perder-se no emaranhado dos textos é a condição básica de quem busca uma ponta de meada enquanto promessa de nova escritura - a questão da autoria transborda o campo moral e se torna um dilema de ordem estética. Em outro texto de pé de página, o Piglia-detetive não só comenta que Arlt considera a escrita como crime porque estaria associada ao roubo, mas também informa que ele teria abdicado das homenagens da crítica em favor de uma maior vendagem de seus livros. Ademais, para o narrador, o crítico seria um delinqüente frustrado ou em potencial, tal como o detetive. Por sua vez, Kostia se considera uma espécie de editor-cafetão pois vende o conto de Arlt. Em síntese, nessa rede, todos são culpados, inclusive aquele que narra já que, logo que obtém o texto de Arlt, passa a listar uma série de reflexões sobre ele, num procedimento típico do ensaísta e, portanto, do criminoso.

Se uma das conseqüências mais interessantes da polêmica empreendida por Ricardo Piglia em Nome falso está ligada à questão da autoria, tal debate só se desenvolve porque ao autor é atribuída a mera função de editor da obra. Ao deslocar a propriedade textual, Piglia não só obtém a liberdade necessária para se colocar como personagem de si mesmo como também para atribuir a autoria de "Luba" a Roberto Arlt quando, na realidade, trata-se da apropriação do conto "As trevas", do escritor Leônidas Andreiev. ${ }^{8}$ O processo de construção de Nome falso revela que, embora os críticos literários Piglia e Kostia disputem um manuscrito inédito atribuído a Roberto Arlt, o apêndice oferecido ao leitor constitui, de fato, um texto apropriado de outro escritor e maquiado pelo Piglia-editor. Contraditoriamente, ao final da trama detetivesca, Kostia publica o

${ }^{8}$ FERRO, 1992. 
manuscrito sob o título de "Nome falso: Luba" e atua como um Max Brod às avessas, já que assume a falsificação da autoria, desde o título do conto furtado. Sendo um conto dentro de outro, "Luba" contém muitas citações e correções nas notas de rodapé, cuja função seria criar a ilusão de que toda a história de sua escritura, perda e procura seria verdadeira. Assim, ao deslocar-se de mão em mão, essa carta roubada leva o leitor a acessar não só o relato, mas também a história de sua criação, leitura e circulação. O mesmo processo é replicado no esboço de romance, presente em Nome falso e também atribuído a Arlt - o leitor lê o diário de Lettif, a história de Lettif, a montagem dessa história e a história de sua leitura pelo narrador de Nome Falso, que inclusive organiza a recepção do texto, através de orientações de leitura que funcionam também como subtítulos. E, finalmente, o destinatário desse hipertexto deve concluir que tudo isso é encenação, embora remeta à realidade das polêmicas relações entre ensaio e literatura.

Nesse caso, tal como ocorre nas produções de Borges, as notas nos pés de página são o espaço da crítica e da reflexão sobre o texto situado na parte superior da folha de papel. São elas que permitem o estabelecimento de uma prática dialógica, em que muitas vozes interferem na elaboração e recepção de uma escrita que, por isso mesmo, transforma-se em lugar de cruzamento de vários discursos sociais.

\section{Os editores e o pastiche}

Num ensaio de 1989, Wander Melo Miranda já mostrava como o trabalho de pastiche de Em liberdade e Nome falso criava um narrador identificado com o leitor "na tarefa de escarafunchar arquivos e textos, levantar dados, fazer conjeturas, seguir pistas labirínticas, decifrar letras esmaecidas, correr atrás de cartas e diários perdidos, maquinar, tramar, fraudar ..." De fato, o pastiche garante ao autor a complexidade de uma forma em que a criação de um texto também implica a produção de um tipo de leitura e de leitor, 
por sua vez capazes de reconhecer nos textos precursores os elementos que contribuem para circunstanciar a produção da obra. Na paródia e na paráfrase, obras e autores mantêm sua identidade, à medida que o texto primeiro configura um centro fixo em torno do qual se move o texto replicante. O pastiche, entretanto, não cuida apenas da remissão a um texto, mas da releitura de uma forma de contar histórias que envolve outros textos produzidos por determinado autor, sua história de vida, suas histórias de leituras e escrituras.

Segundo Schneider, o pastiche "libera a vontade profunda da leitura: lemos verdadeiramente um livro quando dele não podemos mais nos desfazer, só podemos refazê-lo, contrafazê-lo, idéia que converge com a idéia moderna de que é o leitor que, pela primeira vez, faz o livro". ${ }^{10}$ Argumenta, ainda, Schneider que o pastiche tem efeitos opostos aos do plágio, à medida que permite a encenação consciente e declarada de um precursor considerado digno de homenagem. Constituindo uma forma de renovação das narrativas exatamente quando elas apresentam sinais de esgotamento, o pastiche configura um recurso de atualização dos relatos e autores que, em algum momento da historiografia literária, foram responsáveis por relevantes mutações discursivas. Assim, os requisitos necessários para um autor "fazer de conta" que é seu precursor exigem o estabelecimento de uma rede textual onde ambos se deslocam, superpondo-se e mesclando-se de tal forma que certos traços da obra-pastiche passam a ser percebidos na obra pastichada. Proceder como se fosse Graciliano Ramos, Cláudio Manuel, Roberto Arlt ou Leônidas Andreiev exige do autor uma capacidade superior de identificação com o outro, fato que lhe custa o questionamento de sua própria identidade autoral. Desdobrar-se em atitudes miméticas e, ao mesmo tempo, escapar da repetição,

9 MIRANDA, 1989.

${ }^{10}$ SCHNEIDER, 1990. 
apresentando um novo jeito de narrar, parece ser o objetivo dos autores que, na América Latina contemporânea, escrevem histórias que buscam recontar a História da nação. Atuar como se fosse um outro não significa apenas reler seu texto enquanto unidade mínima do processo de composição ficcional, mas homenagear e problematizar sua função como fabulista por excelência de uma comunidade lingüística. Nesse caso, Silviano e Piglia não fogem ao critério geral, que desde sempre tem sido usado para a consagração de um autor, e que se vincula à capacidade demonstrada por ele para tramar os relatos fundacionais de seu grupo étnico, de sua tribo ou nação: quando elegem Graciliano Ramos e Roberto Alrt como seus respectivos precursores, estão também escolhendo uma determinada narrativa de nação e de mundo imaginada por esses pais literários.

Entretanto, o gesto fundacional de Santiago e Piglia esvaziase pela delegação da autoria a um outro, que libertaria os escritores de sua tarefa principal e os transformaria em simples editores. Da mesma forma, a corrida editorial atrás de inéditos funciona como uma caricatura dos mitos engendrados a partir da crença na origem do texto e na propriedade intelectual. Certas formas anacrônicas, como as cartas e os diários, ou intervenções paratextuais, como as notas de edição e os rodapés, além de caracterizarem a função editor como uma problematização da autoria, também indicam as mutações que poderão levar a narrativa contemporânea latinoamericana à invenção de novos gêneros, garantidores da reciclagem textual e da superação do esgotamento de certas formas. 


\section{Bibliografia}

BRATOSEVICH, Nicolás. Ricardo Piglia y la cultura de la contravención. Buenos Aires: Atuel, 1997.

FERRO, Roberto. Homenaje a Ricardo Piglia y/o a Max Brod. In: JITRIK, Noé (comp.). SYC. n.3. Buenos Aires, set. 1992.

MIRANDA, Wander Melo. A liberdade do pastiche. 34 letras. Rio de Janeiro, n.3, p.172-177, mar. 1989.

PIGLIA, Ricardo. Nome falso - bomenagem a Roberto Arlt. Trad. Heloisa Jahn. São Paulo: Iluminuras, 1988.

PIGLIA, Ricardo. Respiração artificial. Trad. Heloisa Jahn. São Paulo: Iluminuras, 1987.

PIGLIA, Ricardo. Moedas falsas no mercado literário. Entrevista realizada por Maria Antonieta Pereira et al. Minas Gerais. Belo Horizonte, n. 1168, p. 10-12, 3 ago. 1991. Suplemento literário.

SANTIAGO, Silviano. Silviano Santiago, no corpo da escrita. Entrevista realizada por Maria Antonieta Pereira e Cleide Simões. Minas Gerais. Belo Horizonte, n. 1168, p. 2-4, 3 ago. 1991. Suplemento literário.

SANTIAGO, Silviano. Em liberdade. Rio de Janeiro: Paz e Terra, 1981

\section{Resumo}

Análise da função editor como recurso de composição das obras Em liberdade,de Silviano Santiago, e Nome falso bomenagem a Roberto Arlt, de Ricardo Piglia.

\section{Resumen}

Análisis de la función editor como recurso de composición de las obras Em liberdade, de Silviano Santiago, e Nome falso bomenagem a Roberto Arlt, de Ricardo Piglia. 